\title{
Performance of HPV E6/E7 mRNA Genotyping Test on Paired Cervical Cancer Exfoliated Cells and Formalin Fixed Paraffin Embedded Tissues
}

\author{
Sunyoung Park ${ }^{1}$, Hyeyoung Wang ${ }^{2}$, Sunghyun Kim ${ }^{3}$, Geehyuk Kim ${ }^{1}$, Sungyoung Bong ${ }^{1}$, \\ Hyoungsoon Jang ${ }^{1}$, Sangjung Park ${ }^{4}$, Kooyeon Hwang and Dongsup Lee ${ }^{6, \dagger}$ \\ ${ }^{I}$ Department of Biomedical Laboratory Science, College of Health Sciences, Yonsei University, \\ Wonju, Gangwon 26493, Korea \\ ${ }^{2} M \& D$, Inc., Wonju Eco Environmental Technology Center, Wonju, Gangwon 26493, Korea \\ ${ }^{3}$ Department of Clinical Laboratory Science, College of Health Sciences, \\ Catholic University of Pusan, Busan 46252, Korea \\ ${ }^{4}$ Department of Biomedical Science, College of Life and Health Sciences, Hoseo University, \\ Asan, Chungcheong 31066, Korea \\ ${ }^{5}$ Department of Clinical Laboratory Science, Seoyeong University, Gwangju 61268, Korea \\ ${ }^{6}$ Department of Clinical Laboratory Science, Hyejeon College, Hongseong, Chungnam 32244, Korea
}

\begin{abstract}
Investigation of human papillomavirus (HPV) in archival formalin-fixed paraffin-embedded (FFPE) material is important for understanding cervical carcinogenesis. The objective of the present study was to identify the high risk HPVs (HR-HPVs) using HPV E6/E7 mRNA testing from archival tissues in cervical cancer and the relation to HR-HPVs genotypes in paired cervical exfoliated cells. HPV E6/E7 mRNA testing and DNA chip testing were performed in 79 paired cervical FFPE tissues and exfoliated cells from women with histologically confirmed squamous cell carcinoma and adenocarcinoma. Overall agreement in HR-HPVs detection from FFPE samples and cytology samples were $98.5 \%$ in HPV 16, 100\% in HPV 18, HPV 31, HPV 33, HPV 58, HPV 66, and HPV 68. Type-specific agreement between FFPE samples and cytology samples was $89.1 \%$ in HPV positive, $93.5 \%$ in HPV 16 and more than $70 \%$ in the other HR-HPVs. In conclusion, HR-HPVs were reliably detected in paired FFPE and cytology samples with some variation in type-specific detection.
\end{abstract}

Key Words: Cervical cancer; Ki67, HPV E6/E7, RT-qPCR, High risk HPVs

\section{INTRODUCTION}

More than 200 human papillomaviruses (HPV) genotypes have been identified to date. In particular, 14 genotypes (HPV 16, HPV 18, HPV 31, HPV 33, HPV 35, HPV 39, HPV 45, HPV 51, HPV 52, HPV 56, HPV 58, HPV 59, HPV 66, and HPV 68) have been classified as carcinogenic or high risk HPVs (HR-HPVs), and HPV 16 and HPV 18 are present in over $70 \%$ of all cervical cancers worldwide (Munoz et al., 2006; Munoz et al., 2003; de Sanjose et al., 2010; Kim et al., 2012).

The risks of developing cancer as well as the distribution of each of the 15HR-HPVs varies in high-grade cervical lesions and cancer (Carozzi et al., 2000; Quek et al., 2013; Tjalma et al., 2013). Diagnosis of HPV infection has been

*Received: September 4, 2016 / Revised: September 29, 2016 / Accepted: September 30, 2016

${ }^{\dagger}$ Corresponding author: Dongsup Lee. Department of Clinical Laboratory Science, Hyejeon College, Hongsung, Chungnam 32244, Korea. Tel: +82-41-630-5342, Fax: +82-41-630-5364, e-mail: dslee@hj.ac.kr

(C) The Korean Society for Biomedical Laboratory Sciences. All rights reserved.

(c) This is an Open Access article distributed under the terms of the Creative Commons Attribution Non-Commercial License (http://creativecommons.org/licenses/by-nc/3.0/) which permits unrestricted non-commercial use, distribution, and reproduction in any medium, provided the original work is properly cited. 
performed from cervical cytology specimens and used in natural history studies, implementation of screening programs, and follow-up of vaccination studies (Wheeler, 2010; Tay and Tay, 2011; Lee et al., 2015). However, cytology specimens often contain larger numbers of HPV infections, most of which are thought to be transient infections, whereas it is assumed that a lesion is caused by one genotype (Mehlhorn et al., 2013; Ho et al., 1995; Lee, 2013; Lee et al., 2011). Thus, identification of HPV in tissue specimens is important to ascertain the causal type involved in HPV-related carcinogenesis.

Formalin-fixed paraffin-embedded (FFPE) tissue samples derived from cervical cancer lesion have advantages such as investigating cancer specific characteristics and identifying clinical outcome but have been limitation to PCR-based assays because formalin fixation induces fragmentation of the nucleic acids. Most HPV assays target the $\mathrm{L} 1$ gene and some other viral oncogenes E6/E7 (Kim et al., 2015). Amplicon sizes range from 65 base pairs (SPF10 primers) to 450 base pairs (PGMY09/11 primers). Several studies revealed the small amplicon length designed PCR such as SPF-LiPA (65 bp) and Inno-LiPA (65 bp) were successfully amplified from FFPE tissue samples (Castro et al., 2015; Dona et al., 2013; Castle et al., 2006; Tjalma and Depuydt, 2013; Gravitt et al., 2007).

In our previous study, the HPV E6/E7 mRNA test in cervical cytology was developed and evaluated (Wang et al., 2015; Munkhdelger et al., 2014). The amplicon size of HPV E6/E7 mRNA test is $70 \mathrm{bp}$, so it was assumed to be possible for studying HPV genotypes in FFPE tissue samples. Given the importance of accurately identifying HPV present in FFPE materials and the lack of studies comparing HPV assays in tissue specimens, our aim of this study was to evaluate the performance of HPV E6/E7 mRNA test on FFPE cervical biopsy samples and to compare the DNA chip results from paired cervical exfoliated cells.

\section{MATERIALS AND METHODS}

\section{Study population}

A total of 79 paired cervical FFPE tissues and exfoliated cells from women patients between the ages of 30 and 85 years (mean 55 years) were retrospectively obtained at the Department of Pathology, Yonsei University Wonju Severance Christian Hospital, Wonju, Republic of Korea, between January 2010 and December 2014. This study was approved by the Institutional Ethics Committee at Yonsei University Wonju College of Medicine (approval number: YWMR-124-010), and all subjects provided written informed consent.

Thin-layer slides were prepared using the Thin Prep 5000 Processor (Product Insight Inc., Acton, MA, USA) according to the manufacturer's instructions. The prepared slides were stained by the Papanicolaou method and evaluated according to the 2001 Bethesda System by certified cytopathologists. After preparing the cytology slide, $1 \mathrm{~mL}$ of solution was removed to a 1.5-mL Eppendorf tube for HPV DNA, and stored at $-72^{\circ} \mathrm{C}$ until used. The tissue biopsy blocks with matched cytology available patients were reviewed by two pathologists. Seventy one squamous cell carcinomas (89.9\%) and eight adenocarcinomas (10.1\%) were histologically confirmed. Three $10-\mu \mathrm{m}$ sections from each paraffin block of cervical tissue were used for total RNA extraction (Table 1).

\section{Nucleic acid extraction}

DNA preparation was performed using HPV DNA Extraction Solution (M\&D, Wonju, Korea), according to the manufacturer's instructions. Briefly, clinical specimens were collected and vortexed for about $1 \mathrm{~min}$. The volume was adjusted to $40 \mathrm{~mL}$ with PBS ( $\mathrm{pH} 7.2$ ) and centrifuged at $2,000 \times g$ at $4^{\circ} \mathrm{C}$ for $30 \mathrm{~min}$. The supernatant was discarded, and $300 \sim 500 \mu \mathrm{L}$ of sterile distilled water was added to the pellet, and the mixture was vortexed and transferred to a 1.5-mL Eppendorf tube. The mixture was then centrifuged at $17,590 \times g$ at $4^{\circ} \mathrm{C}$ for $5 \mathrm{~min}$, and the supernatant was discarded. DNA extraction solution $(100 \mu \mathrm{L})$ was added to the pellet. The mixture was vortexed for $1 \mathrm{~min}$, then incubated at $56^{\circ} \mathrm{C}$ for $15 \mathrm{~min}$ with intermittent tube tapping. After incubation, samples were boiled for $10 \mathrm{~min}$ in a heating block or in a boiling water bath (recommended) and centrifuged at $17,590 \times g$ for $3 \mathrm{~min}$ at $25^{\circ} \mathrm{C}$. The supernatant $(3 \sim 5 \mu \mathrm{L})$ was used as a template for PCR.

Three $10-\mu \mathrm{m}$ sections from each paraffin block of cervical tissue were used for total RNA extraction. Qiagen RNeasy FFPE mini kit (Qiagen, Hilden, Germany) were used 
according to the manufacturer's protocol. Purity and concentration of total RNA were determined by measuring absorbance at 260 and $280 \mathrm{~nm}$ using a spectrophotometer (Infinite 200, Tecan, Salzburg, Austria). All preparation and handling of total RNA was conducted in a laminar flow hood under RNase-free conditions. Isolated total RNA was stored at $-70^{\circ} \mathrm{C}$.

\section{DNA chip}

HPV genotyping via the Goodgene HPV chip (Goodgene Inc., Seoul, Korea) was carried out according to the manufacturer's recommendations. The genotyping method requires nested PCR to amplify the target region using the MY11 and MY9 primers, followed by the GP5/GP6 primer pair. The nested PCR conditions consist of an initial denaturation step for $5 \mathrm{~min}$ at $94^{\circ} \mathrm{C}$, followed by 15 cycles consisting of denaturation for $30 \mathrm{~s}$ at $94^{\circ} \mathrm{C}$ and extension for $30 \mathrm{~s}$ at $65^{\circ} \mathrm{C}$. These cycles are followed by a subsequent 45 cycles consisting of $30 \mathrm{~s}$ at $94^{\circ} \mathrm{C}$ and $30 \mathrm{~s}$ at $54^{\circ} \mathrm{C}$. The final extension step occurs at $72^{\circ} \mathrm{C}$ for $7 \mathrm{~min}$. After PCR amplification of the target region, the subsequent steps were performed according to the manufacturer's recommendation. PCR products were loaded onto the probe-labeled glass Goodgene HPV Chip, and the resulting signal was read using a scanner.

\section{HPV E6/E7 mRNA RT-qPCR assays}

Complementary DNA (cDNA) was synthesized using M-MLV Reverse Transcriptase kit (Invitrogen, Carlsbad, CA, USA) and random hexamers (Invitrogen) according to the manufacturer's recommendations. Briefly, $10 \mu \mathrm{L}$ total RNA was added to master mix containing $10 \mathrm{mM}$ dNTP mix at neutral $\mathrm{pH}, 0.25 \mu \mathrm{g}$ random hexamers, and $5 \mu \mathrm{L}$ DEPC-treated water. Reactions were incubated at $65^{\circ} \mathrm{C}$ for $5 \mathrm{~min}$ and chilled on ice. A mixture of $4 \mu \mathrm{L} 5 \times$ First-Strand Buffer, $2 \mu \mathrm{L} 0.1 \mathrm{M}$ dithiothreitol, and $1 \mu \mathrm{L}$ M-MLV reverse transcriptase (RT) was added, and cDNA synthesis was at $25^{\circ} \mathrm{C}$ for $10 \mathrm{~min}, 37^{\circ} \mathrm{C}$ for $50 \mathrm{~min}$, and $70^{\circ} \mathrm{C}$ for $15 \mathrm{~min}$.

Detection of HPV E6/E7 mRNA in cervical specimens was performed using OPTIMYGENE HPV E6/E7 mRNA RT-qDx assay kits (Optipharm, Osong, Republic of Korea) based on RT-qPCR TaqMan assays using a CFX-96 realtime PCR system (Bio-Rad). Real-time PCR amplification
Table 1. Clinical characteristics on 79 paired cytology and FFPE samples

\begin{tabular}{lc}
\hline \hline Characteristics & $\mathrm{n}(\%)$ \\
\hline Ages & $14(17.7)$ \\
$30 \sim 39$ years & $21(26.6)$ \\
$40 \sim 49$ years & $20(25.3)$ \\
$50 \sim 59$ years & $8(10.1)$ \\
$60 \sim 69$ years & $11(13.9)$ \\
$70 \sim 79$ years & $5(6.3)$ \\
$>80$ years & \\
Cytology & $2(2.5)$ \\
ASCUS & $2(2.5)$ \\
ASC-H & $13(16.5)$ \\
HSIL & $51(64.6)$ \\
SCC & $4(5.1)$ \\
Adenoma & $1(1.3)$ \\
Adeno-Squamous & $6(7.6)$ \\
Not done & \\
Histology & $71(89.9)$ \\
SCC & $8(10.1)$ \\
ADC & $79(100)$ \\
\hline Total & \\
\hline Abrevion: & \\
\hline
\end{tabular}

Abbreviation: atypical squamous cells of undetermined significance (ASC-US), atypical squamous cells - cannot exclude HSIL (ASC-H), high-grade squamous intraepithelial lesion (HSIL), Squamous cell carcinoma (SCC), adenocarcinoma (ADC), and adeno-squamous cell carcinoma (Adeno-Squamous)

of HPV E6/E7 mRNA was in $10 \mu \mathrm{L} 2 \times$ Thunderbird probe qPCR mix (Toyobo, Osaka, Japan), $5 \mu \mathrm{L}$ primer and TaqMan probe mixture, $2 \mu \mathrm{L}$ template cDNA, and DW to final volume $20 \mu \mathrm{L}$. Multiplex RT-qPCR assays detected HPV E6/E7 genes simultaneously in a single tube by incorporating three target-specific TaqMan probes labeled with different fluorophores (FAM, HEX, and Cy5).

\section{Sequence analysis}

The HPV E6/E7 gene region of HPV E6/E7 mRNA positive samples in FFPE cervical cancer tissue was sequenced for differentiating HPV genotypes. Primer sets used to amplify the target HPV E6/E7 gene were 60F-5'-CCGAAAMCGGTKVRTATAAAAGCA-3' and 970R-5'-GTACCTKCWGGATCAGCCAT-3'. Amplified cDNA was 
sequenced using an ABI Prism BigDye Terminator and ABI 3730 automated DNA sequencer (Cosmo Genetech, Seoul, Republic of Korea). Sequences were compared with the National Center for Biotechnology Information GenBank database for species assignment.

\section{Statistical analyses}

HPV genotyping concordance was tested by calculating overall and type-specific percentages of agreement. HPV genotyping results from FFPE specimens was compared to results from cytology specimens as described above, and by creating three categories of agreement (1) Concordant: the number of HPV positive and their specific types are same in both tests. (2) Compatible: the number of HPV positive is same but their specific types are different in both tests. (3) Discrepant: the number of HPV positive and their specific types are different in both tests. The agreement between concordant samples in FFPE and cytology samples was evaluated using the Cohen kappa statistic. Observed $P$-values of less than 0.05 were considered significant.

\section{RESULTS}

\section{Cytologic and histologic diagnosis}

The characteristics of seventy nine samples in this study are shown in Table 1. A total of 79 cytology samples were diagnosed as 2 atypical squamous cells of undetermined significance (ASC-US) (2.5\%), 2 atypical squamous cells cannot exclude HSIL (ASC-H) (2.5\%), 13 high-grade squamous intraepithelial lesion (HSIL) (16.5\%), 51 squamous cell carcinoma (SCC) (64.6\%), 4 adenocarcinoma (ADC) (5.1\%), and 1 adenosquamous cell carcinoma (AdenoSquamous) (1.3\%) and 6 were not tested (7.6\%). Among the 79 FFPE cervical tissue samples were 71 squamous cell carcinomas $(89.9 \%)$ and 8 adenocarcinomas $(10.1 \%)$ were histologically confirmed (Table 1).

\section{Overall HPV prevalence in paired cervical cancer FFPE tissues and exfoliated cells}

In order to identify the HPV genotypes presented in cervical cancer lesion, HPV E6/E7 mRNA expression and its genotypes in 79 cervical cancer FFPE tissues were performed by multiplex RT-qPCR and sequencing. Among the 79 cervical cancer tissues, 65 cases (82.3\%) were HPV E6 E7 mRNA positive and 14 cases (17.7\%) were HPV mRNA E6/ E7 negative. Specifically, HPV 16 and HPV 18 accounted for $68.4 \%$ (54/79) and $10 \mathrm{HR}-\mathrm{HPVs}$ accounted for $13.9 \%$ (11/79), respectively. In paired cytology samples, the prevalence of HPV 16 and HPV 18 were identical (68.4\%). The prevalence of $10 \mathrm{HR}-\mathrm{HPV}$ s and HPV negative in cytology
(A)

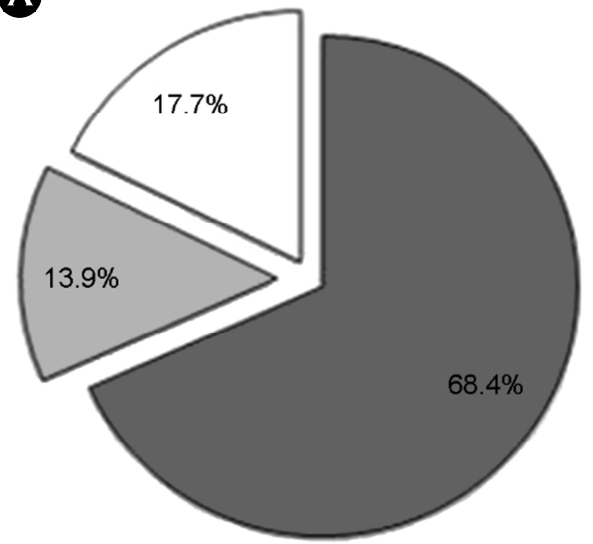

B

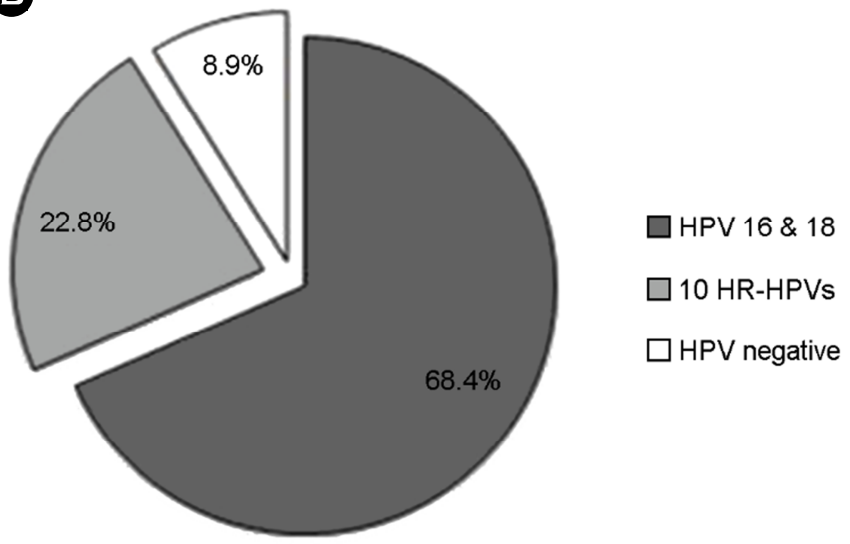

Fig. 1. Overall HPV prevalence in paired FFPE samples (A) and cytology samples (B). In 79 cervical cancer FFPE tissues, HPV 16 and HPV 18 accounted for 68.4\% (54/79) and 10 HR-HPVs and HPV negative accounted for 13.9\% (11/79) and 17.7\% (14/79), respectively. In paired cytology samples, the prevalence of HPV 16 and HPV 18 were $68.4 \%(54 / 79)$ and 10 HR-HPVs and HPV negative accounted for $22.8 \%(18 / 79)$ and $8.9 \%(7 / 79)$. 
samples accounts for $22.8 \%$ and $8.9 \%$, respectively (Fig. 1).

\section{Prevalence of type-specific HR-HPVs in paired cervical cancer FFPE tissues and exfoliated cells}

The most prevalent genotypes in cervical FFPE cancer tissues were HPV 16 (57.0\%), HPV 18 (7.6\%), HPV 33 (5.1\%), HPV 58 (3.8\%), HPV 31 (2.5\%), HPV 66 (1.3\%), and HPV 68 (1.3\%), respectively. Three cases (3.8\%) were multi-infection including HPV 16 with 2 cases (2.5\%) and HPV 18 with 1 case $(1.3 \%)$. The prevalence of genotypes in paired cytology samples was similar to those in FFPE cancer tissues. The most prevalent type was HPV 16 (57.0\%) and followed by HPV 18 (8.9\%), HPV 33 (3.8\%), HPV 58 (2.5\%), HPV 31 (2.5\%), HPV 66 (2.5\%), and HPV 68 (1.3\%). Among the HR-HPVs, one of HPV 39, HPV 45, and HPV 56 each (1.3\%, respectively) were detected. Four cases of other HPVs (other than 16 HR-HPVs, 5.1\%) were detected (Table 2).

\section{Comparison of HPV genotypes in paired FFPE cervical tissues and cervical exfoliated cells}

The paired cervical exfoliated cells among $65 \mathrm{HPV}$ positive cervical cancer FFPE tissues were shown $64 \mathrm{HPV}$ positive cases (98.5\%), except one HPV negative exfoliated cells in HPV 16 positive cervical cancer tissues. The result of the HPV positive between FFPE samples and cytology samples was shown good agreement (Cohen kappa test $=$
0.95 ; concordant rate $=98 \%$ ). To be specific, type-specific agreement between FFPE samples and cytology samples was $89.1 \%(57 / 64)$ in HR-HPVs positive, 93.5\% (43/46) in HPV 16, 71.4\% (5/7) in HPV 18, 75\% (3/4) in HPV 33,

Table 2. HPV genotyping results of paired FFPE samples and cytology samples

\begin{tabular}{|c|c|c|c|c|}
\hline & \multicolumn{2}{|c|}{$\begin{array}{c}\text { FFPE } \\
\text { samples }\end{array}$} & \multicolumn{2}{|c|}{$\begin{array}{l}\text { Cytology } \\
\text { samples }\end{array}$} \\
\hline & Cases, $\mathrm{n}$ & $\%$ & Cases, $\mathrm{n}$ & $\%$ \\
\hline Single infection & 62 & $78.5 \%$ & 69 & $87.3 \%$ \\
\hline HPV 16 & 45 & $57.0 \%$ & 45 & $57.0 \%$ \\
\hline HPV 18 & 6 & $7.6 \%$ & 7 & $8.9 \%$ \\
\hline HPV 31 & 2 & $2.5 \%$ & 2 & $2.5 \%$ \\
\hline HPV 33 & 4 & $5.1 \%$ & 3 & $3.8 \%$ \\
\hline HPV 58 & 3 & $3.8 \%$ & 2 & $2.5 \%$ \\
\hline HPV 66 & 1 & $1.3 \%$ & 2 & $2.5 \%$ \\
\hline HPV 68 & 1 & $1.3 \%$ & 1 & $1.3 \%$ \\
\hline HPV 39 & 0 & $0.0 \%$ & 1 & $1.3 \%$ \\
\hline HPV 45 & 0 & $0.0 \%$ & 1 & $1.3 \%$ \\
\hline HPV 56 & 0 & $0.0 \%$ & 1 & $1.3 \%$ \\
\hline Other & 0 & $0.0 \%$ & 4 & $5.1 \%$ \\
\hline Multi infection & 3 & $3.8 \%$ & 3 & $3.8 \%$ \\
\hline HPV 16 included & 2 & $2.5 \%$ & 1 & $1.3 \%$ \\
\hline HPV 18 included & 1 & $1.3 \%$ & 1 & $1.3 \%$ \\
\hline HPV negative & 14 & $17.7 \%$ & 7 & $8.9 \%$ \\
\hline Total & 79 & $100.0 \%$ & 79 & $100.0 \%$ \\
\hline
\end{tabular}

Table 3. Comparison of HPV genotypes in paired FFPE cervical tissues and cervical exfoliated cells

\begin{tabular}{cccc}
\hline \hline & $\begin{array}{c}\text { HPV positive cases in paired } \\
\text { cervical exfoliated cells (\%) }\end{array}$ & $\begin{array}{c}\text { Concordant cases with } \\
\text { cervical exfoliated cells }\end{array}$ & $\begin{array}{c}\text { Compatible cases with } \\
\text { cervical exfoliated cells }\end{array}$ \\
\hline HPV positive & $64 / 65(98.5)$ & $57 / 64(89.1)$ & $7 / 64(10.9)$ \\
HPV 16 & $46 / 47(97.9)$ & $43 / 46(93.5)$ & $3 / 46(6.5)$ \\
HPV 18* & $7 / 7(100)$ & $5 / 7(71.4)$ & $2 / 7(28.6)$ \\
HPV 31 & $2 / 2(100)$ & $2 / 2(100)$ & $0 / 2(0)$ \\
HPV 33 & $4 / 4(100)$ & $3 / 4(75.0)$ & $1 / 4(25.0)$ \\
HPV 58 & $3 / 3(100)$ & $2 / 3(66.7)$ & $1 / 3(33.3)$ \\
HPV 66 & $1 / 1(100)$ & $1 / 1(100)$ & $0 / 1(0)$ \\
HPV 68 & $1 / 1(100)$ & $1 / 1(100)$ & $0 / 1(0)$ \\
HPV negative & $6 / 14(42.9)$ & $6 / 6(100)$ & $0 / 14(0)$ \\
\hline
\end{tabular}

*HPV multi-infection were included in HPV16 and HPV18 each 
66.7\% (2/3) in HPV 58, and 100\% in HPV 31, HPV 66, and HPV 68, respectively. The compatible cases in paired cervical exfoliated cells and cancer FFPE cells were 7 cases (10.9\%) but the detected HPV genotypes were involved in 12 HR-HPVs (Table 3).

\section{HPV negative in cervical cancer FFPE tissues}

Among the 14 HPV negatives cases in cervical cancer FFPE tissues, cytological diagnosis and its HPV genotypes were compared. Seven cases were shown HPV negative in cervical exfoliated cells. HPVs in seven cases cervical exfoliated cells were detected; two HPV16, HPV 18, HPV 39, HPV52, 66, 68, and three other HPVs were detected. There were no tendency according to ages and cytological diagnosis (Supplementary Data, Table 1). The HPV negative rates in high grade cervical lesions among women ranged from $6.2 \%$ to $18.2 \%$. Regardless of geographic area and sample sizes, approximately 10\% HPV negative were reported (Supplementary Data, Table 2).

\section{DISCUSSION}

Several studies have evaluated the performance of HPV detection from FFPE specimens, but few studies have been compared HPV detection on FFPE samples and paired cytological samples. In the present study, we observed good overall performance for two methods in the detection of HPV from paired FFPE and cytological samples. Our findings are very much in agreement with other reports indicating a good performance of HPV E6/E7 mRNA testing (Kim et al., 2007). Castro et al. showed the $81.7 \%$ to $91.7 \%$ agreement using four different HPV genotyping methods in same FFPE samples (Castro et al., 2015). Our data also showed similar results (82.3\% HPV positive in FFPE samples) to Castro et al., and importantly, oncogenic E6/E7 types of HPV in this study were detected compared to L1 gene based studies. There were some variations of HPV genotypes in three samples for HPV 16 and two samples for HPV 18. The short amplicon size and different collected lesions from cervix such as FFPE samples collected from cancer tissue and cytology samples collected from cervical exfoliated cells may lead to misclassifications of genotypes.
Overall HPV prevalence in the FFPE specimens was lower than in cytology specimens, although the sample size was limited for a formal test. In order to overcome the limitation of the fragmented FFPE samples, the amplicon size of HPVs was designed to be $90 \mathrm{bp}$ and endogenous control GAPDH was designed to be $70 \mathrm{bp}$. GAPDH CT of the $14 \mathrm{HPV}$ negative cases in FFPE samples ranged from 19.4 to 31.2 (Mean 24.6 \pm SD 3.2) was shown valid samples for PCR In addition to amplicon size factor, Donà et al. demonstrated that the sample less detection compared to cytology test, RNA fragmentation by xylene treatment as well as the presence of paraffin, can impact PCR amplification efficiency.

Moreover, in terms of epidemiology, $6.2 \%$ to $18.2 \%$ (approximately 10\%) HPV negative cases in high grade cervical lesions were reported in several studies. Our results also indicated that $8.9 \%$ and $17.7 \%$ of HPV negative cases in cytology and histology samples, respectively. In this study, the 7 cases $(8.9 \%)$ were both HPV negative in paired cytology and histology samples. Moreover, RodriguezCarunchio et al recently reported that HPV negative patients were associated with poor prognosis compared to HPV positive patients (Rodriguez-Carunchio et al., 2015). Therefore, detection of HPV in cervical cancer is highly important, but other molecular markers complementing diagnosis of cervical cancer will be needed.

\section{Conflict of interest}

None.

\section{REFERENCES}

Carozzi F, Ronco G, Confortini M, Noferini D, Maddau C, Ciatto $\mathrm{S}$, Segnan N. Prediction of high-grade cervical intraepithelial neoplasia in cytologically normal women by human papillomavirus testing. British Journal of Cancer. 2000. 83: 1462-1467.

Carozzi M, Tornesello L, Burroni E, Loquercio G, Carillo G, Angeloni C, Scalisi A, Macis R, Chini F, Buonaguro M, Rossi G, Grp W. Prevalence of human papillomavirus types in high-grade cervical intraepithelial neoplasia and cancer in italy. Cancer Epidemiology Biomarkers \& Prevention. 2010. 19: 2389-2400.

Castle E, Sadorra M, Garcia F, Holladay B, Kornegay J. Pilot study 
of a commercialized human papillomavirus (HPV) genotyping assay: comparison of HPV risk group to cytology and histology. J Clin Microbiol. 2006. 44: 3915-3917.

Castro A, Koshiol J, Quint W, Wheeler M, Gillison L, Vaughan M, Kleter B, Van J, Chaturvedi K, Hildesheim A, Schiffman M, Wang S, Zuna E, Walker L, Dunn T, Wentzensen N. Detection of HPV DNA in paraffin-embedded cervical samples: a comparison of four genotyping methods. BMC Infect Dis. 2015. 15: 544.

De sanjose S, Quint G, Alemany L, Geraets T, Klaustermeier E, Lloveras B, Tous S, Felix A, Bravo E, Shin R, Vallejos S, De ruiz A, Lima A, Guimera N, Clavero O, Alejo M, LlombartBosch A, Cheng C, Tatti A, Kasamatsu E, Iljazovic E, Odida M, Prado R, Seoud M, Grce M, Usubutun A, Jain A, Suarez A, Lombardi E, Banjo A, Menendez C, Domingo J, Velasco J, Nessa A, Chichareon C, Qiao L, Lerma E, Garland M, Sasagawa T, Ferrera A, Hammouda D, Mariani L, Pelayo A, Steiner I, Oliva E, Meijer J, Al-jassar F, Cruz E, Wright C, Puras A, Llave L, Tzardi M, Agorastos T, Garcia V, Clavel C, Ordi J, Andujar M, Castellsague X, Sanchez I, Nowakowski M, Bornstein J, Munoz N, Bosch X. Human papillomavirus genotype attribution in invasive cervical cancer: a retrospective cross-sectional worldwide study. Lancet Oncol. 2010. 11: 1048 -1056 .

Dona G, Ronchetti L, Giuliani M, Carosi M, Rollo F, Congiu M, Mazza D, Pescarmona E, Vocaturo A, Benevolo M. Performance of the linear array HPV genotyping test on paired cytological and formalin-fixed, paraffin-embedded cervical samples. J Mol Diagn. 2013. 15: 373-379.

Gravitt E, Van doorn J, Quint W, Schiffman M, Hildesheim A, Glass G, Rush B, Hellman J, Sherman E, Burk D, Wang S. Human papillomavirus (HPV) genotyping using paired exfoliated cervicovaginal cells and paraffin-embedded tissues to highlight difficulties in attributing HPV types to specific lesions. J Clin Microbiol. 2007. 45: 3245-3250.

Ho Y, Burk D, Klein S, Kadish S, Chang J, Palan P, Basu J, Tachezy R, Lewis R, Romney S. Persistent genital human papillomavirus infection as a risk factor for persistent cervical dysplasia. J Natl Cancer Inst. 1995. 87: 1365-1371.

Kim GH, Kim SH, Park SJ, Park SJ, Han L, Yubo R, Li Y, Lee IS, Lee JD, Lee DS. Human papillomavirus prevalence and distribution according to age among korean and chinese women. Korean J Clin Lab Sci. 2015. 47: 259-266.

Kim SH, Lee DS, Kim Y, Kim GH, Park SJ, Choi YI, Kim TU, Park KW, Lee HY. Clinical evaluation of human papilloma- virus DNA genotyping assay to diagnose women cervical cancer. Biomedical Science Letters. 2012. 18: 123-130.

Kim YG, Seo CW, Kim SH, Park YP. Analysis of telomerase activity by HPV E6/E7 expression in SW13. Korean J Clin Lab Sci. 2007. 39: 1-6.

Lee DS, Kim GH, Kim SH, Park SY, Wang HY, Park SJ, Lin H, Ren Y, Yingxue L, Park KW, Lee HY. Human papillomavirus distribution among women in western shandong province, east china using reverse blot hybridization assay. Biomedical Science Letters. 2015. 21: 32-39.

Lee KE. Down-regulation of miR-34a expression in cervical intraepithelial neoplasia with human papillomavirus infection and its relationship with p53 expression. Biomedical Science Letters. 2013. 19: 348-352.

Lee YJ, Jung JH, Park SJ, Jung DY. The relationship between papanicolaou smear test and human papilloma virus DNA chip test in the uterine cervix. Korean J Clin Lab Sci. 2011. 43: 26-32.

Mehlhorn G, Obermann E, Negri G, Bubendorf L, Mian C, Koch M, Sander H, Simm B, Lutge M, Banrevi Z, Weiss A, Cathomas G, Hilfrich R, Wilhelm M, Griesser H. HPV L1 detection discriminates cervical precancer from transient HPV infection: a prospective international multicenter study. Mod Pathol. 2013 26: 967-974.

Munkhdelger J, Choi Y, Lee D, Kim S, Kim G, Park S, Choi E, Jin H, Jeon Y, Lee H, Park H. Comparison of the performance of the NucliSENS EasyQ HPV E6/E7 mRNA assay and HPV DNA chip for testing squamous cell lesions of the uterine cervix. Diagn Microbiol Infect Dis. 2014. 79: 422-427.

Munoz N, Bosch X, De S, Herrero R, Castellsague X, Shah V, Snijders J, Meijer J. Epidemiologic classification of human papillomavirus types associated with cervical cancer. N Engl J Med. 2003. 348: 518-527.

Munoz N, Castellsague X, De B, Gissmann L. Chapter 1: HPV in the etiology of human cancer. Vaccine. 2006. 24 Suppl 3: S3/ $1-10$.

Oh K, Alemany L, Suh I, Rha H, Munoz N, Bosch X, Quint W, Lloveras B, Klaustermeier E, De sanjose S, Shin R. Typespecific human papillomavirus distribution in invasive cervical cancer in Korea, 1958-2004. Asian Pac J Cancer Prev. 2010. 11: $993-1000$.

Quek C, Lim K, Domingo E, Soon R, Park S, Vu V, Tay H, Le T, Kim T, Vu Q, Cao T, Limson G, Pham T, Molijn A, Ramakrishnan G, Chen J. Human papillomavirus type distribution in invasive cervical cancer and high-grade cervical 
intraepithelial neoplasia across 5 countries in asia. International Journal of Gynecological Cancer. 2013. 23: 148-156.

Rodriguez L, Soveral I, Steenbergen D, Torne A, Martinez S, Fuste P, Pahisa J, Marimon L, Ordi J, Del M. HPV-negative carcinoma of the uterine cervix: a distinct type of cervical cancer with poor prognosis. BJOG. 2015. 122: 119-127.

Tay K, Tay K. The impact of cytology screening and HPV vaccination on the burden of cervical cancer. Asia Pac J Clin Oncol. 2011. 7: 154-159.

Tjalma A, Depuydt E. Cervical cancer screening: which HPV test should be used--L1 or E6/E7? Eur J Obstet Gynecol Reprod Biol. 2013. 170: 45-46.

Tjalma A, Fiander A, Reich O, Powell N, Nowakowski M, Kirschner B, Koiss R, O'leary J, Joura A, Rosenlund M, Colau B, Schledermann D, Kukk K, Damaskou V, Repanti M,
Vladareanu R, Kolomiets L, Savicheva A, Shipitsyna E, Ordi J, Molijn A, Quint W, Raillard A, Rosillon D, De souza C, Jenkins D, Holl K. Differences in human papillomavirus type distribution in high-grade cervical intraepithelial neoplasia and invasive cervical cancer in Europe. Int J Cancer. 2013. 132: 854-867.

Wang Y, Park S, Kim S, Lee D, Kim G, Kim Y, Park H, Lee H. Use of hTERT and HPV E6/E7 mRNA RT-qPCR TaqMan assays in combination for diagnosing high-grade cervical lesions and malignant tumors. Am J Clin Pathol. 2015. 143: 344-351.

Wheeler M. HPV genotypes: implications for worldwide cervical cancer screening and vaccination. Lancet Oncol. 2010. 11: 1013-1014. 